\title{
PARA QUE A GEOGRAFIA MUDE SEM FICAR A MESMA COISA ${ }^{1}$ For that geography changes without staying the same
}

\author{
Milton SANTOS 2
}

Quando de sua primeira fundação oficial no fim do século XIX, a Geografia não pode tirar completamente as conseqüências de nenhum dos fundamentos filosóficos que buscava: guardou uma retórica guardada para o homem, mas foi jogada, com os pés e mãos atados, a serviço de todo tipo de poder. A recém-criada Geografia Colonial, a idéia de região imbricada a gênero de vida, as diversas modalidades de culturalismo, eram o lado instrumental que, na prática, faziam desaparecer a possibilidade de realmente se alcançarem os proclamados princípios da atividade e da unidade da terra, assim como outros postulados.

Como em toda fase de crise, como foi aquela em que a Geografia oficial se fundou, nem todos rezavam pela mesma cartilha, havendo os que propugnavam uma ciência mais engajada com a construção de um futuro melhor para o homem, onde ele estivesse. Mas a corrente instrumentalista ganhou, ainda que alguns propusessem um discurso humanista e até, possivelmente, nele acreditassem.

Com as duas guerras e sobretudo após a segunda grande guerra, a mesma busca de renovação e o mesmo divórcio fundamental entre posições: de um lado, as preocupações sociais, de outro os mandamentos do utilitarismo. A primeira corrente deixou como herança uma certa preocupação com o bem comum, mas faltava, em bom número de casos, a elaboração de uma teoria solidamente estabelecida, fundada, a um tempo, nos fatos e na contribuição cada vez mais ampla de ciências que então se renovavam ou criavam. Foi desse modo que as condições se mostraram maduras para que a corrente já nascida utilitária, metamorfoseando antigas posições em novos aspectos e múltiplos disfarces, e ajudada pelas novas exigências de realização da economia, terminasse prevalecendo.

Conforme já o escrevemos alhures, ${ }^{3}$ a Geografia acabou por se tornar a viúva do espaço, indiferente à sorte do homem. O que preocupa essa Geografia é o homem médio e não o homem verdadeiro, e a sociedade considerada como criadora de espaços é a sociedade "global" e não a sociedade tal como ela é, dividida em classes. Tal ponto de partida constitui, o essencial das preocupações e da pesquisa geográfica, e termina aparecendo como se fosse o seu objeto, graças aos recursos postos à disposição dos que, conscientemente ou não, preferem tais idéias.

Felizmente, há os que se rebelam contra tal maneira de interpretar a face da terra a sua transformação pelo trabalho dos homens. Há mais de dez anos, na Europa como na América Latina, nos Estados Unidos e no Canadá como na Austrália, firmam-se relações em múltiplas direções, revestindo uma direcionalidade maior ou menor, mostrando sinceridade maior ou menor, num movimento semelhante àquele que, sob a impulsão de

\footnotetext{
${ }_{1}^{1}$ Artigo originalmente publicado no Boletim Paulista de Geografia, n. 59, p. 5-22, 1982. Agradecemos ao estagiário Luciano Félix da Silva pelo trabalho de digitação do original.

${ }^{2}$ Professor Adjunto Doutor do Depto. Geografia UFPR.

${ }^{3}$ Tratamos amplamente desse assunto em nosso livro Por uma Geografia Nova, São Paulo: Hucitec, 1982.
} 
Pierre George e Jean Dresch, se esboçara dentro das fronteiras da França após a Segunda Guerra Mundial e ainda agora produz os seus frutos.

No âmbito internacional, a Geografia está hoje, novamente, marcada por uma oposição de tendências. ${ }^{4}$ De um lado, os que não desejam que a História se faça em favor dos povos dependentes e das classes oprimidas. Do outro, os que pugnam por uma nova ordem socialmente mais justa.

Entre os primeiros, surgem novas formas de apresentação de velhas posições, tanto mais perigosas quanto mais bem revestidas, mas há, também, uma busca de parecer outra coisa, um mimetismo cuja identificação nem sempre é fácil. A reencadernação da Geografia Cultural, o neodarwinismo redivivo sob a capa de sociobiologia e um humanismo de fachada, onde se incluem postulações fenomenológicas "sui-generis".

\section{NEOCULTURALISMO, NEODARWINISMO, SOCIOBIOLOGIA}

A Geografia Cultural de Sauer e de Gorou está sendo novamente promovida como um enfoque fundamental à compreensão do espaço. ${ }^{5}$ Há cerca de 40 anos, esse método conduzia a esconder as variáveis cuja dimensão ultrapassava aquelas da área estudada ${ }^{6} \mathrm{e}$ atribuía à cultura particular a uma sociedade um papel que, de fato, deveria ser buscado no âmbito de uma economia mais geral cujo funcionamento, sobretudo nos países dependentes ou colonizadores (não se falava ainda em subdesenvolvimento), pode ser explicado sem uma vontade de ir procurar e localizar interesses distantes, os interesses das grandes potências, ao mesmo tempo que as coisas internas.

Nos tempos atuais, os equívocos que o enfoque cultural suscitava se tornam mais numerosos e mais evidentes, devido à internacionalização da economia. Regressar a esse método de interpretação da realidade equivale a querer eliminar os efeitos perversos de uma dependência econômica aumentada e a impor, como se fosse legítima, uma interpretação segundo a qual devese buscar explição para as dificuldades de países pobres e dependentes em causas endógenas, mais culturais que econômicas.

Pode-se dizer que as dificuldades com as quais se defronta o sistema capitalista no momento atual exigem que a nova moralidade dos negócios, a ética das grandes empresas transnacionais, também encontre sua expressão nas ciências sociais. Estas são chamadas a dar sua contribuição à elaboração da nova ordem, através da codificação de novas regras de intercâmbio entre países, firmas e pessoas, em detrimento da moral tradicional que o próprio capitalismo se havia imposto em sua fase liberal. Trata-se, na verdade, da justificação do egoísmo em todas as escalas, desde a das relações internacionais à das relações interpessoais. O amoralismo ao qual as ciências do homem são convidadas parece indispensável para atribuir uma roupagem de idéias a um capitalismo tornado cada vez mais autoritário, carapaça pseudocientífica indispensável a manter ao preço da violência, se necessário, a dominação sobre os recursos que constituem a base material do sistema, cada dia mais estreita.

É nessa mesma ordem de idéias que se busca reviver o neodarwinismo, através da sua renovação e incorporação às diversas ciências sociais.

Uma certa Geografia já se havia apropriado no passado da corruptela do darwinismo, a que Appleman preferiu apelidar de "darwinisticismo". Daí a observação de Dickinson (1969, p. 189) ao escrever que o realmente significativo desenvolvimento do conhecimento humano, em sua relevância quanto ao desenvolvimento da geografia moderna, deu-se no terceiro quartel do século XIX, com o impacto do pensamento evolucionista de Darwin (após 1859). ${ }^{7}$

Não deve causar espanto que, numa fase de crise histórica aguda, um novo apelo seja feito às idéias de Darwin, como apoio à justificação do uso do poder dos mais fortes sobre os mais fracos.

A crise de nossos dias é feita também de confrontações numerosas entre detentores de matériasprimas e seus potenciais usuários, de fornecedores de trabalho e emprestadores de capital. Como os que dominam a cena não desejam abandonar essa arena privilegiada - embora cada vez mais contestada -, a

\footnotetext{
${ }^{4}$ Um estudo fundamental das tendências recentes da Geografia é o de GILLES SAUTTER (1975), que constitui uma tentativa bem sucedida de apresentar de modo objetivo - e também crítico - as diversas tendências filosóficas atuais e o modo como se apresentam na prática geográfica em diversos países.

${ }_{5}$ A propósito da renovação do enfoque culturalista ver, entre outros, NEWSON, Linda, Cultural Evolution: a basic concept for human and historical geography, Journal of Historical Geography, n. 2, p. 239-255, 1976.

6 "O desenvolvimento da Geografia Cultural utilizou-se da reconstrução, em uma área, de culturas sucessivas, começando pela mais antiga até chegar à mais recente de todas" (SAVER, 1962, p. 33)

${ }^{7}$ Sobre esse tema consultar, por exemplo, Stoddart, D. P. Darwin's Impact on Geography. Annals, Association of American Geographers, v. 56,1966, p. $683-689$.
} 
solução é o uso da violência, ainda que apresentada sob novos modelos de sofisticação. A universidade teria que ser chamada a dar forma a novas justificações e, entre as formas renovadas do darwinismo social, criou-se mesmo uma nova disciplina, cuja rápida expansão vai, talvez, buscar sua explicação em sua utilidade. Referimonos à Sociobiologia, que fornece também à Geografia um novo embasamento. ${ }^{8}$

É, aliás, à mesma inspiração que se deve o esforço de valorização da linguagem como forma de interpretação dos fatos correntes. Trata-se menos da linguagem como expressão da sociedade e cuja construção se assemelha à do espaço humano, e mais da linguagem chamada "ordinária", resultado de um discurso da moda, hoje imposto facilmente às populações, como mediação perversa tomada indispensável entre a cultura profunda e a cultura de massa. A "manipulação da linguagem" sugerida por um geógrafo americano, constitui, certamente, um novo disfarce para o neopositivismo, doutrina já surrada em nossa disciplina (SYMANSKI, 1976). ${ }^{9}$

Mas, o prato de resistência de Symanski é o seu estudo intitulado, em associação com Burley, Geography and Natural Selection Revisited, uma espécie de apelo ao passado, como o título explicita. ${ }^{10}$ Para envolver-se com a moda da Sociobiologia, ele toma como ponto de partida um adepto fervoroso do chamado determinismo geográfico: Huntington (1924).

A aplicação da Sociobiologia equivaleria à utilização de uma espécie de neodarwinismo moderno em Geografia. Aos países e às regiões seria aplicado o princípio da seleção natural, que acaba por consagrar os mais fortes e destruir os mais fracos, como resultado de uma lei inevitável que encontra similitude no próprio comportamento da natureza. Tal lei da floresta aplicada à Geografia mostra-se útil à explicação tanto das diferenças também em outras frentes, como através do humanismo e da fenomenologia.

Entre os que pregam uma Geografia "humanística", a começar pela obra pioneira de Yi-Fu Tuan $(1965,1971$, 1974) estão praticamente os mesmos que sugerem a introdução de um enfoque fenomenológico em Geografia (e vice-versa). Edward Relph produzia, em 1970, um artigo para sugerir as relações entre fenomenologia e Geografia, antes de publicar sua tese em 1973. Seu livro Place and Placelesness (1980) é um grande esforço na mesma direção. Aliás, Yi-Fu Tuan havia, também, escrito nos Annals of the American Association of Geographers um artigo em sentido idêntico.

Buttimer redigirá, em 1974 o seu belo ensaio sobre Values in Geography, e, a pretexto de uma leitura dos filósofos existencialistas, proporá, em 1976, em esboço de uma fenomenologia do espaço. Outros geógrafos, sobretudo nos Estados Unidos, ocuparam-se de fenomenologia, como Walmsley (1974), Mercer e Powell (1972) e Billinge (1977) ou do humanismo, tais como Guelke (1974)e Entrikin (1976). Mas outros esforços foram nessa mesma linha e, se não podemos citar todos eles, seria injusto esquecer o trabalho pioneiro de Lowenthal (1961).

Todos esses estudos revelam diversas modalidades de interesse pelo homem, na sua qualidade de indivíduo, ${ }^{11}$ mas raramente concluem por fazer proposições concretas e viáveis em vista de uma mudança social que possa assegurar a chegada de uma nova situação. Podese dizer que, em sua maioria, eles não ultrapassam o plano dos votos piedosos; ou que seu interesse humano é apenas literário. Também se poderia criticá-los pela falta de coerência filosófica que a abundância e o amontoado de citações só faz tornar mais clara. Trata-se de um humanismo sem o homem verdadeiro e total, de uma moralidade sem conseqüência política. $O$ discurso epistemológico correspondente é freqüentemente confuso e a escolha das bases filosóficas de discussão é parcial. Ensaios mais bem construídos, como os de Buttimer, poderiam tirar mais partido do enfoque fenomenológico para mostrar como "o dinamismo do mundo vivo" depende de um processo que vai, incessantemente, da sociedade ao espaço e vice-versa. Mas, o encasulamento nas idéias de Heidegger acarreta uma concepção individualista e idealista, cujo resultado mais claro é o de substituir a praxis coletiva por uma praxis individual, suprimindo, assim, a possibilidade de captar o movimento da sociedade e do espaço como dois dados contraditórios e, ao mesmo tempo, complementares.

Aquilo que se chama a prática individual não pode ser confundido com a prática coletiva, ou melhor, com a

\footnotetext{
${ }^{8}$ Sobre esta questão ver vários autores citados nas referências. 605-614

${ }^{9}$ SYMANSKY, Richard The manipulation of ordinary language. Annals, Association of American Geographers, 1976, n. 4, v. 66, p.

${ }^{10}$ Esse longo trabalho de Richard Symansky e Nancy Burley foi publicado nas Discussion Paper Series n. 25, da Universidade de Siracuso. O debate foi retomado aos cuidados de David J. Robinson, que reuniu trabalhos de nada menos que oito colegas, sob o título Comments on Geography and Natural Selection, publicado na mesma coleção de 1977, sob o número 26.

11 ... "o enfoque humanista jamais será realmente popular. A razão não vem apenas do fato de que ele parecerá muitíssimo menos eficiente do que a manipulação direta do meio físico. Uma razão mais forte é que poucas pessoas se preocupam profundamente em si mesmas com o seu próprio ser. O conhecimento de si mesmo, que é a mais alta recompensa da aventura humana, foi sempre coisa suspeita na cultura ocidental" (YI-FU TUAN, 1976, p. 275/6).
} 
prática social. O que se chama de prática individual são os comportamentos dos indivíduos na vida corrente, conjunto de atitudes e de gestos com os quais cada homem se insere na vida de sua própria coletividade como produto e como cidadão. Desse tipo de prática, diz-se freqüentemente que ela comporta uma parcela importante de escolha pessoal, de indeterminação e do que se chama sorte.

A prática social é, na verdade, coisa diferente. Ela é um resultado direto das necessidades sociais, num lugar dado e num momento dado e, dessa maneira, ela se impõe a todos os que participam da coletividade, seja qual for sua categoria, nos mencionados lugar e momento: por isso, ela é exterior aos indivíduos e se sobrepõe a todos e a cada qual como necessária, isto é, como uma necessidade.

É à prática social que se deve reservar a fórmula simplificada de prática ou praxis. Sem isto, tornar-se-ia impossível apreender e materializar o próprio objeto da atividade do conhecimento. Se levarmos em conta as praxis individuais ou, melhor dito, as correspondentes a cada indivíduo, encontraríamos uma multiplicidade de objetos de referência. Desse modo, a realidade, o objeto real, pareceria pulverizado, dividido em tantos objetos particulares quantas são as pessoas a quem sua realidade concerne. Em outras palavras, o objeto em si perderia sua realidade e, então, nenhum conhecimento dele como o que ele é, seria possível.

O que, na verdade, ocorre é que a prática, a praxis, é, antes do mais, uma realidade estrutural, estruturada e estruturante ao mesmo tempo; assim ela depende estreitamente da totalidade social e não o contrário. Os comportamentos dos indivíduos, isto é, as praxis individuais, são subordinados, estruturados pela praxis social. A liberdade que é freqüentemente reconhecida aos agentes não é outra coisa senão sua participação nas praxis coletivas, por intermédio de uma escolha limitada de opções já incluídas na própria estrutura.

Smith (1979) sugeriu que, através da popularidade alcançada pela fenomenologia, a porta ficava aberta para uma renovação do positivismo geográfico, apresentado sob novas cores.
Podemos acrescentar que, dessa maneira, não apenas o passo definitivo não foi dado para a ingente tarefa de filosofar em nossa disciplina, isto é, para a expansão de uma filosofia do espaço concreto que se beneficiasse da contribuição daquilo que Moscovici (1977) chamou de história humana da natureza. ${ }^{12}$

Falta-nos, na verdade, essa necessária articulação entre o pensamento filosófico e o nosso objeto de conhecimento, o chamado espaço geográfico.

Mais de uma vez, geógrafos têm falhado no seu desejo de transportar para a Geografia noções apresentadas ou maduramente adquiridas no convívio dos livros de filósofos. Usando mal essas muletas, é pouco freqüente que consigam fazer avançar a nossa disciplina neste ou naquele ponto.

A questão não é simples. A filosofia na Geografia supõe, para sua eficácia, uma filosofia da Geografia. Em outras palavras, é preciso pensar a nossa disciplina dentro, e não fora. Sem esse pensamento de dentro, o que se obtém é, apenas, um fraseado elegante, paramentado com citações bem arrumadas, mas só. Um grande número de artigos e mesmo de livros recentemente publicados nos Estados Unidos corresponde ao modelo acima desenhado.

Qual a razão de um resultado tão reles? A razão está no simples fato de que, quando se trata de um ramo particular do conhecimento, a filosofia particular respectiva só se pode fazer ao redor de um objeto compatível e previamente preciso. Em nosso caso, por exemplo, sem isso não há como começar, nem como terminar, assim como a teoria da Geografia - se queremos ter uma - é a teoria do espaço do homem, uma filosofia da Geografia, se for admitido utilizar essa palavra, será uma filosofia do espaço do homem. Isto supõe que dois termos se ponham como princípio e fim do raciocínio: a natureza e a produção. Assim, conhecemos o espaço tal qual ele é, soma de coisas "naturais" e de coisas "fabricadas" e síntese dialética dessas duas séries de coisas, movida pela própria produção, isto é, pelo homem e sua história. Fora daí, do que podemos falar? Como transferir categorias universais $\mathrm{e}-$, portanto - fixas e gerais para a interpretação do que tem vida graças ao fato de reproduzir,

12 "Para irmos além do empirismo e das debilidades do pragmatismo, é necessária uma discussão mais explícita da filosofia e da sociedade. É necessário reformular o quadro conceitual e a filosofia social da Geografia. Geografia é menos interessante do que poderia ser, em parte porque sua filosofia é geralmente implícita e conservadora e, na verdade, sua "filosofia" freqüentemente é pouco mais que "metodologia". Isso tem contribuído para a síndrome do "vagão banda de música". Em vez de analisar suas insatisfações, alguns geógrafos se tornam "beachcombers wading in the shallows of theyr disciplines" (por exemplo, a biologia). Isto também implica em que alguns tópicos (por exemplo, a pobreza) são necessariamente mais fecundos que outros (como a indústria). Mas o que se necessita não é "a topical veneer, or guiltridden introspection" acerca dos valores pessoais. Uma análise científica adequada dos "desprivilegiados" e a produção como distribuição da riqueza. Deveria, igualmente, incluir a respectiva produção de ideologias. Isso exige um "rekinalling of geography's holistic and historical hadition" (como exemplificado na escola escocesa, com H. J. Fleure) e reintegrando-a com os ganhos obtidos com as "revoluções" quantitativa e comportamental, das quais até certo ponto foi a vítima" (ANDERSON, 1973, p. 5). 
em circunstâncias concretas específicas, a totalidade, em mudança, do Ser? As próprias noções fundamentais, eternas e universais de essência, processo, função e forma ganham uma nova dimensão quando aplicadas, ao conhecimento específico do uso do território, objeto de nossos esforços científicos.

\section{SEDUÇÕES E RISCOS DO ENFOQUE MARXISTA}

Diante desse projeto, o enfoque marxista aparece pleno de seduções: noções como a de modo de produção e de formação social abarcam o todo e as partes, permitem levar em conta o movimento da história, a interação entre a vida e as formas que cria ou encontrou.

Adotar um enfoque marxista também significa que o ponto de vista da economia política deve estar presente na análise do que chamamos regiões e nos estudos urbanos.

Eis como Vaggagini e Demmateis interpretam os recentes progressos do marxismo em Geografia.

Face à recusa (da geografia tradicional) em associar as estruturas territoriais e as relações sociais de produção, as quais são inteiramente funcionais em relação aos interesses das forças sociais dominantes, que essa estrutura produz e transforma de fato, a análise dialética e a teoria marxista abrem hoje seu caminho na geografia dos países capitalistas e isto se dá tão rapidamente que, recentemente, as contradições do capitalismo atingiram aspectos de enorme gravidade no quadro de uma crise que interessa ao conjunto da sociedade ocidental e que se manifesta de uma forma mais ou menos clara através de uma utilização do espaço geográfico fundada sobre o desperdício dos recursos e sobre a injustiça social (VAGGAGINI, et al. 1976, p. 140).

Essa perspectiva deverá exigir um esforço exemplar, uma vez que boa parte da literatura marxista concernente ao espaço adota um cunho mais crítico do que explícito, conduzindo, não raro, a um discurso apologético e ideológico, na medida em que vemos conceitos já estabelecidos brigando entre si, em lugar de assistirmos a uma nova geração conceitual, a ser pacientemente obtida pela análise dos fatos. Sugerimos, assim, que um ponto de vista substantivo seja escrupulosamente respeitado.
Temas como o da luta de classes e o da acumulação do capital são, também, muito freqüentes. Muitos se contentam de mencionar esses dois temas fundamentais, pelo fato de que falam por si mesmos. Nada, certamente, é mais enganador. Tanto a discussão sobre a luta de classes quanto a que se faz sobre a acumulação do capital são termos escorregadios. Freqüentemente conduzem a tautologias que, por isso mesmo, em nada contribuem para ajudar num esforço analítico, pois nem uma nem a outra são objetos em si. Exigem, por isso mesmo, um grande esforço intelectual, para permitir a separação das variáveis que deixem entender os respectivos processos. Não basta, em nenhum caso, alinhar um conjunto de proposições de economia política em geral. Temos de partir do espaço como objeto concreto construído e a ele voltar, e assim contribuir, segundo os pontos de vista propostos, para a edificação das bases, que tanto nos fazem falta, de uma teoria do espaço humano. Será, sem dúvida, uma teoria menor embutida no bojo da teoria maior, que é a teoria social.

Os diversos temas deveriam ser tratados segundo um ângulo espacial e à maneira sistêmica. ${ }^{13}$ Por exemplo, como considerar um dado espaço, cidade ou região, através da espacialização de conceitos como forças produtivas, meios de produção, força de trabalho, relações sociais de produção, etc. Nesse sentido, um esforço sistemático globalizante ajudaria a dar ainda maior conteúdo às hipóteses fundamentais propostas - luta de classes e acumulação de capital -, vistas como elementos da construção (produção e da evolução) reprodução de uma dada fração de espaço e da problemática que tudo isso envolve.

A consideração do papel do Estado é importante. Seria, igualmente, prudente, dar também relevo ao papel das outras instituições, acima e abaixo do Estado. A ação concreta, inclusive sobre o território, se faz por intermédio dessas instituições ou organizações, formais ou informais. A própria explicação do desenvolvimento desigual no espaço encontra na dialética entre essas instituições e seus aparelhos uma de suas explicações. Aí também se insere o tema do planejamento, cujos feitos vão além da simples reprodução das forças produtivas, porque conduz à criação deliberada de forças produtivas novas, algumas das quais até então insuspeitadas.

E em todos os casos, impõe-se dar ênfase a aspectos menos estudados da transformação do espaço geográfico como resultado da fase mais recente do desenvolvimento do capitalismo (o período científicotécnico atual), enfatizando à luz das novas condições

13 “...Não é a primazia dos motivos econômicos na explicação histórica que constitui a diferença decisiva entre o marxismo e o pensamento burguês, mas o ponto de vista da totalidade" George LUKACKS (1968). 
históricas, a nova significação das categorias marxistas de análise, o que deveria levar à incorporação no desenvolvimento teórico (se não nos exemplos concretos) de autores pós-marxistas. Isso não apenas ajudaria a interpretação das realidades atuais, como reduziria o risco de dogmatismo.

\section{EXISTENCIALISMO E PRÁTICA MARXISTA}

Entre os grandes problemas da prática marxista continuam a estar a questão do encontro fecundo entre o teórico e o empírico e da redescoberta pelo indivíduo do seu próprio futuro, nas dobras do movimento social. $\mathrm{Na}$ medida em que a internacionalização da economia deu à ciência geográfica, como teoria locacional da sociedade e teoria social dos lugares, uma nova dimensão, tanto uma fenomenologia bem entendida, como um existencialismo à moda sartriana aparecem como instrumentos do conhecimento indispensáveis à ação e como componentes de uma renovação do próprio enfoque marxista.

Sartre considerava o marxismo como uma filosofia da qual o existencialismo seria uma interpretação. Desse ponto de vista, um esforço baseado no existencialismo poderia ser de grande auxílio nessa busca. Jaspers escreveu que "pensar o mundo objetivo é (...) negá-lo como subjetivo e anexá-lo à objetividade" (...) "mas o mundo objetivo não pode reivindicar a exclusividade ...." Tal ponto de vista pode conduzir a um encontro com os que, a partir da fenomenologia, recusam o papel histórico das praxis coletivas, redutoras das praxis individuais. ${ }^{14}$ Nesse particular, o ensinamento de Sartre é um bem mais instrutivo. Quando, através, e apesar da prática imposta pela sociedade, o indivíduo é capaz de superar-se, ele entrevê novos caminhos para ele próprio e para a sociedade.

Sabemos das restrições que se fazem, entre muitos marxistas, ao enfoque fenomenológico ${ }^{15}$ e às posições existencialistas, ${ }^{16}$ o primeiro sendo apontado como herético e o segundo como sendo revisionista. Mas a questão do fenômeno, definido como um aspecto do real, somente encontra solução na busca do todo, de onde vêm suas determinações. A decifração do fenômeno tem de passar por uma metodologia capaz de, na prática, realizar uma importante premissa marxista: a da união dos métodos de dedução e de indução mediante o caminho que leva do fato (como forma e como evento) ao conceito e deste, já sob uma feição teórica, regresse ao fato. Como os eventos, junto com as formas, constituem, em cada momento, a historicização geográfica do universo, as disciplinas geográficas não podem prescindir desse método. ${ }^{17}$

Por outro lado, a questão da subordinação, cada vez maior, do homem às ideologias, coloca como crucial o problema de sua liberação. O peso e a sofisticação das instituições e dos seus métodos de ação ensejam a elaboração administrativa de uma segunda natureza humana, moldada à imagem do anti-homem. É pelo mesmo mecanismo que se criam anti-espaços, dos quais as metrópoles - anti-cidades por excelência -, são o exemplo melhor. Pode o homem escapar ao império desta máquina que o tritura, ou sua objetificação é

14 "Pensar o mundo objetivo é, portanto, negá-lo como subjetivo e anexá-lo à objetividade. Mas o mundo objetivo, por sua vez, não pode reivindicar a exclusividade, pois, no momento mesmo em que reduzo tudo a ele, eu me transformo numa pessoa que perde o prumo. $E$ isto pode ser entendido em dois sentidos. Por um lado, fico sendo o sujeito que não tem objeto, mero centro de referência para todo o saber - o que equivale dizer que o princípio da imanência não pode ser deslocado. Por outro lado, quer dizer que o mundo objetivo se ordena no mundo do sujeito que sou. É a partir do meu corpo que se desenrola o espaço, como a partir do meu presente (é) que se desenrola o tempo. Sou eu o "hic et nunc" em que se apóia toda a realidade objetiva. E por mais despojada que ela seja, meu conhecimento fica sempre ligado a meu ponto de vista. Por mais que eu queira deixar de ser o centro, nunca posso colocar-me do ponto de vista de Sírius, que seria o único e o verdadeiro. (Karl Jaspers, visto como no livro de Michel Dufrenne e Paul Ricoeur Karl Jaspers et la Philosophie de l'Existence. Paris: Editions du Seuil. Excerto de um trecho publicado na Folha de São Paulo, 16 abril 1978).

${ }^{15}$ Fenomenologia. 1. Estudo descritivo de um fenômeno ou de um conjunto de um fenômenos em que estes se definem quer por ocasião às leis abstratas e fixas que os ordenam, quer às realidades de que seriam a manifestação. 2 . Sistema de Edmund Husserl, filósofo alemão (1859-1938) e de seus seguidores, caracterizado principalmente pela abordagem dos problemas filosóficos segundo um método que busca a volta "às coisas mesmas", numa tentativa de reencontrar a verdade nos dados originários da experiência (Novo Dicionário Aurélio).

${ }^{16}$ Existencialismo. Corrente de pensamento iniciada por Sören Kierkegaard, filósofo dinamarquês (1813-1855), na qual se distinguem Martin Heidegger, Karl Jaspers (1891) e Jean-Paul Sartre, e para a qual o objeto próprio da reflexão filosófica é o homem na sua existência concreta, sempre definida nos termos de uma situação determinada, mas não necessária - o "ser-em-situação", o "ser-nomundo" -, a partir da qual o homem, condenado à liberdade, por já não ser portador de uma essência abstrata e universal, surge como o arquiteto da vida, o construtor do seu próprio destino, submetido embora a limitações concretas; filosofias existenciais; filosofias da existência (Adaptado de Novo Dicionário Aurélio).

17 "O existencialismo, como o marxismo, dirige-se à experiência de forma a descobrir, por seu intermédio, sínteses concretas; ele apenas pode conceber essas sínteses dentro de uma totalização progressiva e dialética que é nada mais do que história ou - do ponto de vista estritamente cultural aqui adotado - a filosofia tornando-se o mundo (philosophy - becoming - the - world). Para nós, a verdade é algo que está sempre surgindo ou nascendo de novo, ela já foi e ela, de novo, será. É uma totalização que está sempre sendo totalizada". (SARTRE, 1968, p. 30). "Fatos particulares não têm significado próprio; eles não são verdadeiros nem falsos até que sejam relacionados, à realidade em processo, através da medição de várias totalidades parciais" (SARTRE, op. cit. p. 30-31). 
irremediável? O existencialismo de Sartre parece mostrarnos "cientificamente" que o homem não é um ser completamente perdido para o humano, restaurando-nos a confiança no futuro. Não é também esta a visão do marxismo, desde que uma despojada de uma crença mecanicista no econômico ou de toda outra forma de dogma? ${ }^{18}$

Ora, uma ciência do espaço que não se contente, somente, em constatar o presente e deseje contribuir para a reconstrução social deve, forçosamente, valer-se dos instrumentos cognitivos e teóricos que não só avaliem as virtualidades latentes nos indivíduos, mas que através da entrevisão e codificação das possibilidades, também acelerem seu encontro consigo mesmos, isto é, com o provir. ${ }^{19}$

\section{À GUISA DE CONCLUSÃO}

No mercado das idéias geográficas, uma dicotomia aparecia bem clara nos fins do século passado e no começo do atual. Ela foi de distinção menos fácil quando da chamada "revolução teorética". Agora torna-se mais confusa, exigindo um esforço maior de discernimento para separar o joio e o trigo, idéias genuínas e "marketing", gente que assume posições próprias e a malta dos que se põem a serviço de idéias programadas. Uma primeira distinção seria distinguir entre os que utilizam dos recursos intelectuais para ajudar a servir o futuro e os que se esforçam para salvaguardar o passado. Entre estes últimos há aqueles cujos possíveis equívocos são o resultado de convicções cimentadas em uma prática pessoal irreversível que permite falar deles como de pessoas honestas, ao menos com si mesmos. E há os outros, os que se organizam à base de projetos financiados por agências deliberadamente criadas para isso. O objetivo destes últimos, nem sempre clara ou imediatamente discernível, é encontrar argumentos para retardar a inevitável reconquista do homem por si mesmo, e atrasar a construção de um novo mundo.

\section{REFERÊNCIAS}

ANDERSON, J. Ideology in Geography: na introduction. Antipode, v. 5, n. 3, dez. 1973.

BILLINGE, M. In search of Negativism: Phenomenology and Historical Geography. Journal of Historical Geography, n. 3, p. 55-67. 1977.

BUTTIMER, A. Values in Geography, Association of American Geographers. Resource Paper, n. 24, 1974.
Mas, porque toda classificação generalizadora pode levar-nos à uma margem de equívoco, talvez nem seja útil, apontar de forma inquisitorial, mas ingênua, quem são os "bons" e quem são os "vilões". Parece-nos bem mais importante realçar as formas larvares ou camaleônicas que a Geografia vem tomando de uns anos pra cá. São manifestações para as quais se estão abrindo as portas das instituições mais comprometidas com a manutenção de um capitalismo selvagem e que encontra os favores de uma certa finança, corporativa ou oficial, cuja ingerência perversa na atividade intelectual mundial não é suficiente conhecida. Aliás, um traço essencial de sua própria política é exatamente o aliciamento de intelectuais estabelecidos ou emergentes, chegando, mesmo, a empalmar, mediante pecúnia, associações profissionais já estabilizadas.

Todo cuidado é pequeno. É justamente nas fases que a história se acelera, que os conceitos envelhecem mais depressa, abandonados pela realidade em manutenção rápida. É a própria realidade que temos de apreender, para não vermos escapar de nossas mãos a compreensão do Presente e a possibilidade de ganhar o Futuro. Por isso também, em tais fases críticas da História, podem-se distinguir, em matéria de proposições interpretativas do real, duas modalidades extremas ou puras e uma infinidade de posições intermediárias. Cabe lembrar aqui a advertência de GRAMSCI: “... o problema da identidade da teoria e da prática se põe, especial-mente...

Vem, aliás, desse interesse prático, que exige urgente justificação, a possibilidade de uma grande confusão: entre o que espelha o movimento da sociedade como um todo (ainda que sob um aspecto particular) e o que, como particular e se impondo à vista de todos, pode parecer geral, sem todavia, ultrapassar a condição de um fenômeno específico, bem localizado no tempo e no espaço. A expressão de ambas as situações pode, evidentemente, aparecer como se fosse teórica, em termos formais. Mas, de um lado, está a teoria baseada nos fatos, em sua expressão universal; de outro, a fetichização da aparência ou a mistificação da parte como se fosse o todo ou, ainda, do aspecto como se fosse o geral.

BUTTIMER, A. Grasping the Dynamism of Lifeworld. Annals of the Association of American Geographers, v. 66, n. 2, p. 277-292, June 1976.

DICKINSON, R. E. The Makers of Modern Geography. Londres: Routledge and Paul Kegan, 1969.

DORFLES, G. Símbolo, Comunicação y Consumo, Barcelona: Lumen, 1962. 
DINIZ FILHO, L. L. Para que a Geografia mude sem ficar a mesma coisa

DOMERGUES, P. Sociobiology et politique: une "science" à l'heure de austerité. Le Monde Diplomatique, p. 19, ago. 1979.

ENTRIKIN, J. N. Contemporary Humanism in Geography. Annals of the Association of American Geographers, v. 66, n. 4, p. 215-632, Dec. 1976.

FISCHLER, C. Le combat de Richard Lewontin contre la Sociobiologie. Le Monde Dimanche, p. 15, set. 1980.

GRAMSCI, A. Introdución a la filosofia de la praxis. Barcelona: Ediciones Peninsula, 1972.

GUELKE, L. An idealist alternative in Human Geography. Annals of the Association of American Geographers, v. 64, p. 193-202, 1974.

HUNTINGTON, E. Geography and Natural Selection. Annals, Ass. of Amer. Geog. v. 14, 1924.

KATZ-FISHMAN, W.; JAN, F. The politics of Sociobiology. The Insurgent Sociologist, v. 10, n. 1, Summer 1980.

LOWENTHAL, D. Geography, experience and imagination: towards a Geographical epistemology. Annals of the Association of American Geographers, v. 51, 1961.

LUKACS, G. Le marxism of Rosa Luxemburg. History and Class Consciousness. Londres: Merlin Press, p. 27. 1958.

MERCER, D. C.; POWELL, J. M. Phenomenology and related non-positivistic viewpoints in the social sciences. Monash Publications in Geography, n.1, 1972.

MOSCOVICl, S. Essai sur L'historie de la Nature. Paris: Flamarion, 1977.

NEWSON, L. Cultural Evolution: a basic concept fou human historical geography. Journal of Historical Geography, n. 2, p. 239-255, 1976.

RELPH, E. Na inquiry into the relations between phenomenology and geography. The Canadian Geographer, v. 14 , p. 193-201, 1970.

Place and Placelessness. Londres: Pion, 1976.

REVIEWS. Animal Behavior, n. 24, p. 698-718, 1976.

RODRIGUES, A.; LEWONTIN et al. Comments in Geography and natural selection revisited by Symansky and Burley, Dep. Of Geography, Univ. of Syracuse, Discussion Paper Series n. 26, Mar. 1977.

SARTRE, J. P. Being and Nothingness, A phenomenal essay on ontology (1943), Washington Square Press., 1975.
SAUTTER, G. Some thoughts on geography in 1975. International Social Sciences Journal, v. 27, n. 2, 1975.

SAVER, C. Cultural geography. In: WAGNER, P.; MIKESELL, M. Readings in Cultural Geography, Univ. of Chicago Press, 1962.

SCHMIDT, A. The concept of nature in Marx. Londres: NLB, 1975.

SMITH, N. Geography, Science and post-positivist modes of explanation. Progress in Human Geography, v. 3, p. 356383, 1979.

SOCIOBIOLOGY STUDY GROUP, Science for people, Sociobiology - a new biological determinism.

STEVENS, V. J. Sociobiology, Science and Human Behavior, Monthly Review, v. 31, p. 41-49, April, 1980.

STODDART, D. R. Darwin's impact on Geography. Annals of the Assocation of American Geographers, v. 56, p. 683-698, 1966.

SYMANSKY, R. The manipulation of ordinary language. Annals, Ass. of Amer. Geog., n. 4, v. 66, p. 505-614, 1976.

SYMANSKY, R.; BURLEY, N. Geography and Natural Selection Revisited.Departament of Geography, Syracuse University, Discussion Paper, n. 25, Dec. 1976.

TUAN, Y. F. Environment and "World". The Professional Geographer, v.. 17, n. 2, p. 6-8, Sept. 1965.

Structuralism Existencialism, and Environmental Perception. Environment and Behavior, p. 319-331, Sept. 1952.

Geography, phenomenology and the study of human nature. The Canadian Geographer, XV, p. 181-192. 1971 1974a.

Topophilia, Prentice Hall, Englewood Clifs, N. J.,

Space and Place. Humanistic Perespective, Progress in Geography, v. 6, p. 212-52,1974b.

VAGGAGINI, V. e DEMATTEIS, G. I Metodi Analitici della Geographia, Firenze: La Nuova Italia Editrice, 1976.

WALMSLEY, D. J. Positivism and Phenomenology in Human Geography. The Canadian Geographer, XVIII.,1974.

WILSON, E. O. Sociobiology: the new syntesis, Cambridge, Mass: The Belknap Press of Harvard Universiti Press, 1975. 